\title{
Solidaridad religiosa y resistencia al COVID 19 en los cerros de Comas Estudio de La Iglesia Evangélica Peruana en la Periferia de Lima
}

\author{
Dario Paulo Barrera Rivera*
}

\section{Resumen}

La pandemia del COVID 19 llegó al Perú en marzo del 2020 obligando a interrumpir todo tipo de actividades colectivas, entre ellas las religiosas. En la mayoría de los países de América Latina, marcados por grandes desigualdades sociales, el impacto de la pandemia ha sido más fuerte entre la población más vulnerable por causa de su menor capacidad de respuesta y de la desprotección de parte del poder público. Este estudio analiza el impacto de la pandemia en una iglesia evangélica de la periferia de la ciudad de Lima, enfocando las diversas y creativas formas de reacción del grupo religioso. Al intentar resistir a la pandemia en condiciones adversas, la iglesia generó importantes cambios en las celebraciones y en el significado de las mismas. Los vínculos de solidaridad y la importancia de la reflexión bíblica, propia de la tradición protestante, son aspectos centrales de este estudio.

Palabras clave: Pandemia COVID 19, periferia urbana, evangélicos, solidaridad.

\section{Solidariedade religiosa e resistência ao COVID19 nos morros de "Comas"}

\section{Estudo da Igreja Evangélica Peruana na periferia de Lima}

\section{Resumo}

A pandemia do COVID19 chegou ao Peru em março de 2020 obrigando a interromper todo tipo de atividades coletivas, entre elas as religiosas. Na maioria dos países da América Latina, marcados por grandes desigualdades sociais, o impacto da pandemia tem sido maior nas populações mais vulneráveis em razão de sua menor capacidade de

* https://orcid.org/0000-0001-7006-6310. Universidade Federal de Juiz de Fora. É doutor em Ciências da Religião, professor de graduação e pós-graduação em Ciências da Religião da Universidade Federal de Juiz de Fora. dariopbr@terra.com.br . 
resposta e da desproteção por parte do poder político. Esse estúdio analisa o impacto da pandemia numa igreja evangélica da periferia da cidade de Lima, com foco nas diversas e criativas formas de reação do grupo religioso. Ao procurar resistir à pandemia em condições adversas, a igreja gerou importantes mudanças nas celebrações e no significado das mesmas. Os vínculos de solidariedade e a importância da reflexão bíblica própria da tradição protestante são aspectos centrais de este estudo.

Palavras-chave: Pandemia COVID 19, periferia urbana, evangélicos, solidariedade.

\section{Religious Solidarity and Resistance to COVID19 on the Hills of Comas Study of the Peruvian Evangelical Church in the Outskirts of Lima}

\section{Abstract}

The COVID19 pandemic arrived in Peru in March 2020, forcing it to stop all collective activities, including religious activities. In most countries in Latin America, marked by great social inequalities, the impact of the pandemic has been greater on the most vulnerable populations due to its low response capacity and the lack of protection by political power. This study analyzes the impact of the pandemic on an evangelical church on the outskirts of the city of Lima, focusing on its diverse and creative ways of reacting to the pandemic. In seeking to resist the pandemic in adverse conditions, the church made important changes to the celebrations and their meaning. The bonds of solidarity and the importance of biblical reflection, characteristic of the Protestant tradition, are aspects of this study.

Keywords: Pandemic COVID 19, urban periphery, evangelicals, solidarity

Los efectos de la pandemia en países tan desiguales como el Perú han sido de mayor impacto en la población más vulnerable exacerbando las grandes brechas estructurales. ${ }^{1}$ La iglesia aquí estudiada está situada en una región periférica de la ciudad de Lima, el distrito de Comas, uno de los más populosos de la región norte de la ciudad. El nombre de la iglesia en estudio es "Iglesia Evangélica Peruana Comas Km 13", en adelante simplemente "IEP Comas" 13. El texto está organizado en tres partes. En la primer se revisa las características generales del Distrito de Comas destacando elementos sociales, económicos y culturales que permiten comprender la realidad que envuelve a la iglesia en estudio. La segunda parte estudia el impacto de la pandemia en el distrito y en la iglesia como resultado,

CEPAL, Informe anual 2020. Disponible en: https://www.cepal.org/es/comunicados/ pandemia-provoca-aumento-niveles-pobreza-sin-precedentes-ultimas-decadas-impacta

2 Expreso aquí mis agradecimientos a los Hermanos/as, dirigentes de la IEP Comas Km 13 por la enorme gentileza de brindarme acceso a toda la información para esta investigación. 
fundamentalmente, del abandono de parte del gobierno central (el Estado) y las limitaciones del gobierno regional (la Municipalidad). Realidad ésa que antecede a la pandemia y se extiende hasta los años setenta cuando surge el Distrito de Comas y también la iglesia en estudio. La tercera parte aborda la reacción del grupo religioso a la pandemia ${ }^{3}$, la forma como se organizaron para resistir su impacto, muchas veces fatal, la creatividad para reformular las actividades religiosas y la ampliación de la comprensión religiosa de la sanidad y la enfermedad. Este estudio cuestiona esa perspectiva revisando las prácticas sociales y culturales del lugar y la respuesta organizada de una iglesia enclavada entre los "Cerros de Comas".

Se trata, evidentemente de un estudio de caso. Además de investigación bibliografía sobre las periferias de la región norte de la ciudad de Lima este estudio se apoyó en observación remota de las actividades religiosas. Fue decisivo el hecho de que todas esas actividades se hacen en la plataforma "zoom" y los líderes de la iglesia las mantienen gravadas y me fueron gentilmente facilitadas. También hicimos entrevistas remotas a cinco integrantes de la iglesia, entre ellos a dos líderes/as (Presidente de la sociedad de jóvenes y Presidenta del consistorio) y a tres miembros sin cargo. Para determinar el perfil socioeconómico del grupo aplicamos un cuestionario al $10 \%$ de los miembros. Los datos, entrevistas y cuestionarios fueron hechos entre los meses de setiembre a noviembre del 2020.

$\mathrm{La}$ "IEP" es una de las primeras denominaciones protestantes que se establecieron en el Perú desde fines del siglo XIX e inicios del XX. Se ha extendido en las diversas regiones del país y en especial en la ciudad de Lima. Es heredera de una versión del protestantismo reformado y recoge buena parte de su tradición litúrgica y organizacional (KESSLER 1993). Su liderazgo es compuesto por pastores ordenados, pero mayormente por pastores laicos lo que les da a las iglesias locales importante autonomía en la gestión religiosa de los "bienes de salvación". De los aspectos litúrgicos es importante destacar que esa denominación ha conservado de la tradición protestante reformada (WILLAIME 1992) la centralidad de la Biblia en su sistema religioso. La Biblia es objeto de interpretación cuidadosa en los cultos dominicales y las reuniones de "estudio bíblico" tienen singular importancia en la congregación observada para este estudio.

Una versión primordial de esta investigación, aún en estado inicial, fue presentada en el Seminario "Reacciones religiosas al COVID 19" organizado por la Asociación de Científicos Sociales de la Religión del Mercosur en el mes de setiembre de 2020. Agradezco mucho a los participantes que me permitieron con el diálogo nuevas perspectivas. 


\section{"La estera se ha convertido en casas de tres pisos": invasión y organización popular}

La región metropolitana de la ciudad de Lima tiene 50 distritos. La ciudad creció rápidamente a partir de los años setenta acogiendo migrantes del interior del país y constituyendo un verdadero mosaico cultural de orígenes (especialmente) de la región andina, además de la región amazónica. La cultura y el lugar de origen continúan siendo importantes y acompañan la experiencia de establecimiento de los migrantes en las regiones periféricas al paso de las generaciones (GOLTE 2018). Lima es una ciudad del litoral peruano y el centro histórico está a sólo 30 minutos del puerto "El Callao". El crecimiento de la ciudad se dio hacia el norte, hacia el este y hacia el sur constituyendo lo que en Lima se denominan "conos" urbanos. El distrito de Comas, localizado en el cono norte de la ciudad es uno de los más poblados a nivel nacional, tiene alrededor de 520,000 habitantes según el último Censo del año 2017 (Gestión 2017). Comas ha crecido subiendo los cerros y no había otra alternativa. Conforme iban llegando los migrantes ocupaban terrenos baldíos subiendo los cerros que constituyen ya parte de la Cordillera de los Andes. La principal avenida de Comas es la Av. Tupac Amaru, inaugurada con ese nombre en la época del gobierno del General Juan Velazco Alvarado. En los años 70 Comas llegaba hasta el Km 11 de dicha avenida. En poco tiempo llegó al Km 18 y luego al Km 21 constituyendo el distrito vecino de Carabayllo. De manera que al hablar del crecimiento de Comas expresamos inevitablemente el proceso de población de los "cerros de Comas" a ambos lados de la Av. Tupac Amaru. La iglesia que aquí estudiamos se constituye en el año 1972 en el entones lejano Km 13 de la Avenida Tupac Amaru.

Los fundadores de Comas eran migrantes que invadieron terrenos baldíos. De hecho, fueron conocidos como en muchos lugares de las periferias de Lima, como "invasores". Invasores de terrenos de una antigua hacienda. Las declaraciones de dos fundadores de Comas dan testimonio de los orígenes y las difíciles condiciones de los primeros pobladores. Juan Sosa dice "Si la estera se ha convertido en ladrillo, en casa de tres o cuatro pisos es por el esfuerzo de todos". Margarita Estremadoyro afirma "nuestros padres migrantes sembraron barriadas en los cerros". ${ }^{4}$ Tanto Sosa como Estremadoyro son parte de la segunda generación de los "invasores" de "los cerros de Comas". Llama la atención la referencia al origen migrante

4 "Los fundadores de Comas" vídeo, FITECA 01/03/2015. Disponible en https://www. youtube.com/watch?v=Y4y6e8 hWpw. Acceso: 20/06/2020 
de los padres y el registro de que ellos constituyeron espacios de vecindad ("barriadas") en un lugar inhóspito. Cuando aconteció la invasión el lugar era inhabitado y una extensa subida. La referencia a los "cerros" es inevitable. Tanto físicamente como simbólicamente es muy importante. Una cadena de cerros separa Comas del distrito de San Juan de Lurigancho (otro de los distritos más poblados de la ciudad. Los "cerros" son parte de la geografía de Comas. La frontera Este del distrito la constituyen un conjunto de cerros que llegan hasta cerca de $900 \mathrm{msnm}$. Antes de la pandemia la IEP Comas 13 organizaba caminatas a los cerros los fines de semana como parte del trabajo pastoral que busca revalorizar los beneficios del ejercicio físico para la salud. Una de las líderes de la IEP km 13 nos informó que las caminatas a los cerros son una tradición antigua en la iglesia, pero que se ha renovado en los últimos años. Se hacía con el objetivo de incentivar la confraternidad y la salud:

Cuando todavía no había muchas casas en las partes altas de los cerros íbamos hasta donde no había casas y terminábamos con un devocional, canciones y disfrutábamos de una vista panorámica de la ciudad. En las últimas generaciones se han realizado de manera más frecuente, recorriendo un tramo mayor y llegando inclusive hasta el distrito de San Juan de Lurigancho al otro lado de los cerros. Les ponemos nombres a las caminatas, por ejemplo "caminata por la salud, "caminata contra la corrupción", etc. Y se han añadido tanto jóvenes como adultos. Las caminatas que teníamos programas para este año se han suspendido por la pandemia. (Entrevistada "J").

Subir a los cerros puede considerarse un acto simbólico de retorno a los orígenes de los fundadores migrantes. Retorno, sin duda reinterpretado, porque los cerros son ahora un desafío físico más que una experiencia mítica. La modernidad urbana ha transformado el sentido de las relaciones con la naturaleza. Sin embargo, como veremos, más adelante, la pandemia ha provocado, por lo menos en la iglesia en estudio, una preocupación inédita con relación a la salud y el bienestar con la naturaleza.

A lo largo de las tres últimas décadas del siglo XX la ocupación de las tierras y la construcción de viviendas muy precarias fue dando lugar al surgimiento de formas inéditas de organización popular. ${ }^{5}$ Nos interesa

\footnotetext{
5 Refiriéndose a los años ochenta Matos dice: "Hasta en el terreno de la organización política se hace sentir la presión del nuevo estilo: formas inéditas de lucha popular se manifiestan e imponen su presencia fuera del juego oficial de las izquierdas y derechas. Contra ellas todas las tácticas y estrategias de represión convencional se siguen mostrando inadecuadas.
} 
prestar atención a las acciones sociales organizadas pues la iglesia en estudio ha mostrado un importante nivel de trabajo organizado contra la pandemia. En ese sentido es importante conocer el escenario de la organización social para enfrentar las necesidades básicas. Repasamos brevemente los orígenes de la organización popular en Comas en los años 80 y recogemos datos de su estado al inicio de la pandemia. Eso nos permitirá una valoración apropiada del papel desempeñado por la IEP Comas 13. Ese fenómeno de la organización popular ha sido común en la formación de todas las periferias de la ciudad de Lima. La organización popular en el Cono norte ha sido muy importante especialmente en los años 80. Los estudios al respecto muestran que 94\% de las organizaciones populares surgieron a partir de 1981 (JOSEPH 1999: 100). La mayor parte las organizaciones populares del Cono norte estaba constituida y dirigida por mujeres. Son organizaciones dedicadas a enfrentar una necesidad básica como la alimentación.

En sus inicios estas organizaciones surgen con un carácter fuertemente asistencial y bajo la modalidad de entrega de víveres a cambio de trabajo individual. Sin embargo, a fines de la década de los 70 y comienzo de los 80 , con la experiencia de las mujeres en la lucha por servicios urbanos y el apoyo a las huelgas prolongadas del magisterio nacieron las ollas comunes, que luego servirían de referencia para la organización de los comedores populares. Es así como surgen los primeros comedores autogestionarios. Primero en Comas, luego en El Agustino, Villa El Salvador y así sucesivamente. De esta manera, las organizaciones populares femeninas, pese su sujeción a las decisiones y estilos de cada período de gobierno, fueron ganando autonomía. A la vez, las mujeres organizadas fueron acentuando su protagonismo comunal y familiar. (JOSEPH 1999: 101. El subrayado es nuestro).

El papel de los comedores populares fue muy importante en los años 90. Había cerca de 4,600 comedores populares, autogestionarios, que brindaban alimentación a bajo costo a más de medio millón de personas. Antes del auge de los comedores populares hubo, en la primera mitad de la década de los años 80 un importante antecedente de organización popular impulsado por el alcalde Lima Alfonso Barrantes. Frente a la alarmante desnutrición infantil y en cumplimiento de lo ofrecido durante su campaña

El proceso y crecimiento de la contestación económica de masas que en estos años ha dado lugar a la atención de gobernantes y estudiosos, no se muestra sino como la forma más visible de un proceso de desborde popular, de mucho más amplia envergadura sin el cual resulta incomprensible" (MATOS 1984, 88). 
como candidato de la Izquierda Unida, Barrantes cumplió con creces su propuesta de ofrecer 1 millón de vasos de leche diarios "a los niños desnutridos de los barrios de Lima". Ese programa generó la organización de miles de "Comités de vaso de leche" en toda Lima metropolitana. En el 2019 los Comités de vaso de leche aún subsisten en Comas (dirigidos ahora por la municipalidad), especialmente dedicados a reducir la anemia severa de cerca de 9 mil niños de ese distrito. ${ }^{6}$ El protagonismo de la participación organizada y autogestionaria de las pobladoras en la gestión se ha reducido bastante ${ }^{7}$ y con eso diversos problemas han surgido. Una tesis sobre el programa del Vaso de Leche en Comas en los años 2017 y 2018 lo constata:

Según se afirma por diversas personas inmersas en este programa social, las irregularidades están presentes, tal es así, que se ha llegado a realizar marchas en contra de la mala implementación que se realiza en el distrito de Comas, en donde las madres y las presidentas de los distintos Vasos de Leche, buscan que se mejore la calidad de los insumos destinados a los programas, así como el cambio de los proveedores puesto que se presume que los insumos años tras años son entregados por la misma empresa, por un precio mayor al del mercado y con una calidad inferior al mismo. (CASTILLO 2018: 13)

En el presente año (2020) la pandemia mostró las fragilidades de los programas sociales del Estado, entre ellos el del Vaso de Leche. En el mes de junio del 2020 diversas denuncias periodísticas muestran el abandono del Estado a la población más vulnerable, por ejemplo, al Hacientamento Humano "El Aposento Alto" de Comas. ${ }^{8}$ Las entrevistas realizadas para este estudio con miembros de la IEP Km 13 comprobaron que durante la pandemia ninguna de sus familias había recibido ayuda prometida por el Estado: ni los bonos, ni las cestas básicas. Es decir, además de no recibir la ayuda prometida para amenizar el impacto de la pandemia, parte de los

\footnotetext{
6 "Lucha frontal contra la anemia no se detiene en distrito de Comas", MUNICOMAS, disponible en https://www.municomas.gob.pe/noticia/1061. Acceso: 20/09/2020.

7 En los años 80 la organización popular era promovida e incentivada por los gobiernos municipales, que eran de izquierda: "EL inicio de gestiones municipales por un frente de izquierda en el distrito de Comas, desde 1981 hasta fines de 1992, que trató de ejercer un gobierno local en relación permanente con las organizaciones populares" (HUAMÁN 199: 172).

8 "Hacentamiento Humano de Comas no es beneficiado con el Vaso de Leche", El Comercio, 30 de junio del 2020. Disponible en https://elcomercio.pe/videos/pais/asentamientohumano-de-comas-no-es-beneficiado-con-el-programa-vaso-de-leche-videos-pais-nnavamtv-noticia/ .Acceso: 99/07/2020
} 
programas sociales que ya no funcionaban bien dejaron de funcionar o de llegar a los sectores más vulnerables.

Otro tipo de organización popular que se destaca en Comas es más reciente y del campo artístico cultural. Miembros de la iglesia en estudio han participado de sus actividades. En el año 2001 y por iniciativa de pobladores del barrio de La Balanza en Comas se organizó la primera FITECA: Fiesta Internacional de Teatro en Calles Abiertas. El nombre expresa muy bien el objetivo fundamental de llevar teatro y cultura al espacio de la calle, lo que implica su libre acceso, participación y gratuidad. El proyecto FITECA se ha consolidado en las dos décadas del presente siglo proponiendo una quiebra del acceso elitista al teatro, abriendo la participación de la población como actores y espectadores al mismo tiempo. Se realiza una vez al año a lo largo de una semana siempre en espacio público. Edgar Mego, uno de los pobladores participantes en la FITECA del 2019 afirma:

Para mí FITECA es la oportunidad que propone este barrio para ser un país distinto. Para mí FITECA es el espacio donde muchos soñadores de origen popular nos reunimos para apostar por una sociedad más justa, más igualitaria, más colorida, más diversa y por supuesto como una comunidad humana que proyecta mucha esperanza. ${ }^{9}$

Miembros de la IEP Km 13 han participado varias veces de la FITECA. Una de las entrevistadas nos informó que varios adolescentes fueron parte de ese grupo artístico. "Los hijos de la familia Z, miembros de nuestra iglesia, animaron a los adolescentes a participar de los talleres de FITECA". (Entrevistada J)

\section{La pandemia sube a los cerros de Comas}

El aumento de las víctimas de la pandemia, en número de contagiados y de víctimas fatales, ha sido muy evidente en el Perú a pesar de la temprana decisión del gobierno central de una cuarentena obligatoria en todo el país. En el mes de agosto el Perú ya era el primero a nivel mundial en número de víctimas y óbitos con una tasa de mortalidad de 87,53 óbitos por cada 100 mil habitantes. ${ }^{10}$ Ese aumento rápido llegaría más temprano a las

\footnotetext{
9 Disponible en https://www.youtube.com/watch?v=JxwHgr89Lek. Acceso: 27/10/2020

10 Información de la BBC a partir de datos de la Universidad Johns Jopkins. Disnonible en: https://www.bbc.com/portuguese/internacional-53974414
} 
regiones más vulnerables ${ }^{11}$ como las periferias de la capital, entre ellas el distrito de Comas. A menos de un mes del inicio de la pandemia el Alcalde de Comas, Raul Díaz Pérez informaba en una entrevista que ya había en Comas 200 infectados. ${ }^{12}$ Hay que recordar que esos casos no resultaban de una aplicación masiva de pruebas. Eran casos clínicamente comprobados, en consecuencia, el número debe sin duda haber sido mucho mayor. Dadas las condiciones precarias para enfrentar la pandemia desde el gobierno regional (la Municipalidad) y la gestión del gobierno central que actuaba siguiendo la agenda neoliberal de no descuidar la economía, el número de víctimas aumentaría inevitablemente en los meses siguientes. Todos los entrevistados/ as para este estudio afirmaron que al no recibir ningún tipo de ayuda parte de la familia se vio obligada a salir a trabajar para atender las necesidades básicas, especialmente de alimentación. De hecho, en el mes de octubre la pandemia ya había cobrado 871 víctimas fatales. Una ceremonia, con misa incluida, en homenaje a esas víctimas se realizó en la explana del Centro Cívico de Comas el 24 de octubre. En el lugar se colocaron 871 sillas con los nombres de las víctimas y con una bandera peruana en cada silla. En la ceremonia y con amplia divulgación en las redes sociales mediáticas se usaba el slogan "Una bandera por cada peruano caído en Comas". ${ }^{13}$ Veamos

11 Entendemos el concepto de "vulnerabilidad" en el sentido propuesto por Kowarick (2009) que se refiere a la mayor o menor capacidad de reacción frente a riesgos potenciales. El concepto es muy rico y no permite simplificar la situación de pobreza. No existen personas vulnerables y no vulnerables. Existen niveles de vulnerabilidad. Nadie es plenamente invulnerable. El grado de vulnerabilidad depende de un conjunto de variables sociales y económicas. Más vulnerable serían, por ejemplo, las personas con menos escolaridad y también sus descendientes, porque las desventajas de la baja escolaridad se extienden a la próxima generación. La renta familiar será, más o menos, suficiente o insuficiente según el número de personas que componen la familia y su situación laboral estable o inestable. La posibilidad de enfrentar gastos extraordinarios, extra cotidianos, como los que una situación de emergencia demanda, será menor en una familia con más personas desempleadas o con salarios menores. El acceso a los servicios de salud, públicos o privados, expresa de forma clara la desigual vulnerabilidad en el Perú contemporáneo. Es evidente así que los sectores sociales más vulnerables han estado más expuestos a la emergencia sanitaria provocada por la pandemia.

12 Entrevista del Alcalde de Comas, Raul Díaz, a El Comercio (22/04/2020). Disponible en: https://elcomercio.pe/lima/sucesos/coronavirus-peru-comas-raul-diaz-pide-al-gobiernousar-el-presupuesto-del-foncomun-para-ayudar-a-vecinos-ante-la-pandemia-del-coronaviruscovid-19-estado-de-emergencia-cuarentena-nndc-noticia/?ref=ecr

13 https://elcomercio.pe/lima/coronavirus-en-peru-el-emotivo-homenaje-a-las-871-victimasdel-covid-19-en-comas-fotos-nnpp-noticia/?ref=ecr. La palabra "caído" en el slogan tiene evidente connotación a una guerra contra el virus. Como veremos más adelante, la gestión política y económica del enfrentamiento a la pandemia representaba una guerra desigual para la población más vulnerable. En ese sentido era una guerra perdida de antemano. 
primero las condiciones generales de la gestión de la pandemia de parte del gobierno central y luego sus efectos en Comas a partir de las voces de los miembros de la iglesia en estudio.

La economía del país ha sido considerada como una de las más "saludables" de la región en las últimas décadas. Sin embargo, de forma simultánea la desigualdad ha aumentado mostrando la ineficacia de las promesas neoliberales (TANAKA, 2011). Esa relación entre economía "saludable" y aumento de la desigualdad, es directamente proporcional. Cuanto más saludable la economía mayor también es la desprotección social y económica de la población. En el Perú del año 2019 la mayor parte de la población no tenía empleo estable, pues más del 70\% de los trabajadores eran informales, ${ }^{14}$ en consecuencia, sin derechos sociales. Los servicios básicos de salud tampoco están asegurados para la mayor parte de la población. A lo largo de la pandemia la situación de vulnerabilidad de amplios sectores de la población de la mayoría de los países de América Latina ha quedado al desnudo. La pandemia ha expuesto la gravedad del no acceso a los servicios de saneamiento (agua y desagüe) de importantes parcelas de la población. En la entrevista de abril del 2020 al Alcalde de Comas, citada anteriormente, afirmaba que el 70\% de la PEA ("población económicamente activa") de Comas "es independiente", es decir, trabaja por cuenta propia, no tiene ninguna estabilidad laboral. Al mismo tiempo afirmaba que a un mes de cuarentena "la gente sale a ganarse la vida" en una diversidad de emprendimientos informales. En los meses siguientes la Municipalidad, con ayuda de la policía e incluso de soldados de la base militar de Collique (distrito fronterizo a Comas), actuaron violentamente para cerrar varios mercados informales que funcionaban en las calles ("paraditas") porque se habían convertido en focos de infección y diseminación del virus. Las "paraditas" son fuente de renta de los pobladores de Comas. El hecho expresa claramente la contradicción inevitable entre la "salud" de la economía nacional y la precariedad laboral de la población.

En los últimos 30 años en el Perú se estableció una economía neoliberal que beneficia a las grandes empresas, deja al mercado al libre

14 Según datos del INEI (Instituto Nacional de Estadística e información) recogidos por la Defensoría del Pueblo, en el 2019, 72\% de la población económicamente activa estaba en el sector informal, llegando en algunas regiones hasta el 91\%. Cf. Estado de emergencia sanitaria: el problema de la informalidad laboral en una economía confinada". Disponible en: https://www. defensoria.gob.pe/wp-content/uploads/2020/04/Serie-de-Informes-Especiales-N\%C2\%B002-2020-DP-Problema-de-la-informalidad-laboral-en-una-economia-confinada.pdf 
juego y exige mínima o nula intervención del Estado en la economía. En la primera década del siglo XXI el fracaso de ese modelo se hizo evidente por la escandalosa desigualdad que genera incluso en los países más desenvueltos (STIGLITZ 2013) Todos los gobiernos desde el primer gobierno de Alberto Fujimori al inicio de los años noventa hasta el actual gobierno de substitución de Francisco Sagasti fueron en esa dirección. En esos treinta años todos los gobiernos han resultados de procesos democráticos y los que se salieron de las reglas del juego democrático, más tarde (como el de Fujimori) o más temprano (como el de Manuel Merino en plena pandemia) fueron obligados a renunciar presionados (especialmente) por la movilización popular. Sin embardo sería extremadamente limitado afirmar la legitimidad política, porque elegidos democráticamente, de los gobiernos neoliberales. En realidad, se trata de la "captura del estado" por parte de los grandes intereses económicos representados por corporaciones nacionales e internacionales (DURAND 2020) detrás de las cuales se encuentran, en el ámbito nacional, un pequeño número de familias. Al cabo de 30 años de bonanza económica para esas elites nacionales la pandemia llega para desvelar casi repentinamente una sociedad profundamente desigual. El "Documento de trabajo Perú" n.6 de 2017 de la OXFAM ya revelaba que las metas de erradicar la pobreza extrema para 2021, prometidas por el entonces Presidente Pedro Knczynski, no sólo que no se cumplirían, sino que retrocederían. ${ }^{15}$ La igualdad política en una sociedad democrática cuyo Estado ha sido reducido a un papel "subsidiario", inclusive para decidir sobre políticas públicas en situaciones de emergencia, resume bien esa situación en la que la desigualdad económica coloca en jaque la igualdad política y social.

El dilema entre mantener una economía saludable o proteger a los más vulnerables se hace notorio con el neoliberalismo, pero no es totalmente nuevo pues está presente desde los orígenes de la democracia republicana en el Perú. En los inicios de las instituciones de salud están instituciones de caridad. Ya en el siglo XX era necesario ir de la caritativa hacia la gestión pública moderna en una sociedad de derechos ciudadanos, entre ellos el derecho a la salud. Era necesario substituir una gestión caritativa y de inspiración religiosa por otra científica y médica. Junto al Estado,

Disponible en: https://peru.oxfam.org/sites/peru.oxfam.org/files/file_attachments/ Hacia $\% 20$ d $\%$ C3 $\%$ B3nde $\% 20$ vamos. $\% 20$ Promesas $\% 20$ de $\% 20$ Kuczynski $\% 20$ contra $\% 20$ la $\% 20$ desigualdad $\% 20$ contin $\%$ C3 $\%$ BAan $\% 20$ estancadas $\% 20 \operatorname{tras} \% 20$ un $\% 20$ a $\%$ C3 $\%$ B 1 o $\% 20$ de\%20gobierno.pdf. Acceso en enero de 2021. 
supuestamente soberano, estaban al inicio del siglo XX las grandes empresas (especialmente las mineras) como instituciones importantes para el desarrollo y la modernización del país. Las empresas viven el dilema de reducir los riesgos del trabajo porque necesitan de la mano de obra dispuesta. Pero, al mismo tiempo, las grandes empresas no quieren participar en los costos del Seguro Social al que consideran excesivos. Necesitan obreros saludables y fuertes para el trabajo duro, que inevitablemente afectaría su salud, pero no querían ser copartícipes (las empresas) de los costos de un "Sistema de Salud Público" (DRINOT 2016: 253). ${ }^{16}$

Durante la pandemia la población de Comas ha sentido fuertemente la desprotección del Estado. Lo constatamos en diversas situaciones. Como buena parte de la población tenía solamente un trabajo informal con la pandemia y la cuarentena pararon de trabajar. Una consecuencia de eso fue que dejaron de pagar impuestos cayendo rápidamente la recaudación de la Municipalidad. En ese escenario el Alcalde de Comas hacía, en el mes de abril un pedido al Gobierno central para que autorizase el uso de recursos destinados a inversión pública (FONCOMUN ${ }^{17}$ ) para enfrentar la pandemia. El pedido refleja la situación alarmante. Recién en el mes de agosto el gobierno central decide una transferencia de 199 millones para las municipalidades. ${ }^{18}$ Hay que decir, sin embargo, que en febrero de 2020 la Municipalidad de Comas se encontraba en la lista de municipalidades que había usado cero soles de los recursos de FONCOMUN. ${ }^{19}$ Significa que para 2019 los recursos para inversión (entregados por el gobierno central)

16 Entre otras empresas, en 1936, la Peruvian Corporation y la Cerro de Pasco Copper Corporation, así como las cámaras de comercio de las ciudades más importantes estaban preparando protestas para prevenir la promulgación de las leyes que darían lugar al Seguro Social (DRINOT 2016, 253).

17 "El Fondo de Compensación Municipal (FONCOMUN) es un fondo establecido en la Constitución Política del Perú, con el objetivo de promover la inversión en las diferentes municipalidades del país, con un criterio redistributivo en favor de las zonas más alejadas y deprimidas, priorizando la asignación a las localidades rurales y urbano-marginales del país." Disponible en: https://www.mef.gob.pe/es/transferencias-a-gobierno-nacional-regional-ylocales/base-legal-y-aspectos-metodologicos/fondo-de-compensacion-municipal-foncomun

18 Si tomamos en cuenta que en el país hay 196 gobiernos provinciales, 1678 gobiernos distritales y 2,740 centros municipales, el monto destinado resulta irrisorio. Si se cuenta solamente los provinciales y distritales una distribución igual (el cálculo es mucho más complejo y sigue diversas variables) para todos muestra que cada uno recibiría apenas 106 mil soles.

19 https://gestion.pe/economia/mef-640-municipales-no-han-gastado-ni-un-sol-en-inversionpublica-en-enero-noticia/ 
exclusiva en "zonas alejadas y deprimidas" y "urbano marginales" no habían sido usados por el Alcalde.

Como mencionado anteriormente en octubre el número de víctimas fatales del virus era muy alto, pero sólo en la segunda quincena de noviembre se tiene noticias de la aplicación de exámenes que permitiesen detectar a portadores asintomáticos y proceder a su aislamiento. Sin embargo, el número de pruebas moleculares ha sido insignificante en comparación con el tamaño del distrito.

Se trata de la aplicación de unas 370 pruebas moleculares más para detectar y descartar casos de Covid 19 en la zona de Chacra Cerro y Trapiche de Comas, sectores que comprenden a la Zonal 14 del distrito, a la que se desplazaron cinco equipos de médicos y tecnólogos médicos del Ministerio de Salud, quienes fueron los encargados de aplicar las mencionadas pruebas a los vecinos y vecinas que llegaron hasta el Patio de Honor de la indicada institución educativa en donde se instaló el personal médico. ${ }^{20}$

Los entrevistados (durante el mes de octubre) para este estudio informaron que no habían podido hacerse ninguna prueba. La única excepción fue el del entrevistado "S", un joven de 20 años, líder de la juventud de la iglesia. "S" consiguió terminar ya al inicio de la pandemia un curso superior de diseño técnico. En el mes de setiembre consiguió un empleo temporal y comenzó de inmediato. Para trasladarse a su lugar de trabajo usa el transporte público, normalmente abarrotado de gente, por un recorrido que dura cerca de 2 horas. "S" tomó la iniciativa de hacerse una prueba serológica en una clínica particular que le costó 125 soles. La entrevistada "R", miembro de la iglesia hace 42 años y que perdió al papá por causa de virus nos informó que el descuido en la salud en Comas es grande y desde hace años. Por la gravedad de su padre constató la situación de colapso de los hospitales y la negación de las clínicas particulares a brindar cualquier tipo de atención a quien no podía pagar los precios exigidos por los servicios.

"L", otro de los entrevistados relata que "por lo menos tres familias de la iglesia han sido afectadas fatalmente. Hay padres y abuelos fallecidos y varios adultos con la salud muy vulnerable". "J" precisa esa información diciendo que cinco familias de la iglesia han tenido pérdidas fatales y otras tres familias cercanas también han perdido familiares. Añade también que,

20 Información de la Municipalidad de Comas disponible en: https://www.municomas.gob. $\mathrm{pe} /$ noticia/ 5340 
además de los fallecidos/as, más de 15 personas de la iglesia han sido contagiadas. "S" afirma que no hay un solo hermano/a que se haya librado de ser afectado por el virus. De una forma u otra, física o emocionalmente todos hemos sido afectados".

Ya en el mes de junio la dramática falta de camas del Servicio público de salud se combinaba con la crueldad de los altísimos precios exigidos por las clínicas particulares. Eso a pesar de que desde el mes de abril el entonces Presidente de la República anunciaba un acuerdo para que los costos de servicios de cuidados intensivos de las clínicas privadas fuesen cubiertos con dinero público. En los meses siguientes las clínicas chantajeaban al Estado con altísimos precios, al tiempo que la legislación se presentaba ambigua sobre las posibilidades de que el Estado pueda intervenir o exigir el uso de las clínicas. (BARRERA 2020).

Las características socioeconómicas de las personas que componen la iglesia en estudio la recogimos aplicando un cuestionario al 10\% del total. El número de seguidores es de hasta 50 personas, incluyendo miembros y simpatizantes. En ambos casos los cuestionarios fueron aplicados a personas que durante la pandemia participaban de las actividades virtuales y de las iniciativas para enfrentar la pandemia que veremos más adelante. El cuestionario aplicado a los miembros de la IEP Comas 13 muestra que son familias cuya renta familiar está entre 1 a 3 sueldos mínimos (SMV). El SMV en el Perú es de 930 soles (258 USD). Algunas familias tienen renta familiar menor que $1 \mathrm{SMV}$. La gran mayoría trabajaba, al inicio de la pandemia de forma independiente, sin ninguna estabilidad laboral. La mayor parte vive en casa o departamento alquilado y la relación entre el número de personas que vive en la misma casa es de 1 dormitorio por cada 1,5 personas. La mayor parte ha concluido la educación secundaria. Finalmente, 50\% son adultos mayores. La pandemia profundizó rápidamente la vulnerabilidad social del grupo generando endeudamientos diversos. Los que vivían en casa o departamento alquilado enfrentaron dificultades para pagar el costo del alquiler. Los bajos ingresos no les permitían ningún tipo de gastos extras generados por la pandemia y al cabo de 2 meses del inicio de la cuarentena en la mayoría de las familias alguien tuvo que salir a trabajar, exponiéndose al contagio.

\section{La comunidad religiosa: respuestas a la pandemia}

Las entrevistas realizadas a miembros de la IEP Comas 13 y la observación de los videos de los diferentes videos y "talleres" han sido la 
fuente principal para conocer cómo el grupo religioso reaccionó ante la pandemia. Como es propio en la tradición evangélica la celebración del culto es fundamental. Desde su fundación en el año 1972 es la primera vez que se enfrentaban a la necesidad de interrumpir la celebración de los cultos. Después de una semana del inicio de la cuarentena la iglesia comenzó a organizarse para realizar cultos a distancia y lo han venido haciendo hasta el presente vía la plataforma gratuita "zoom". El reinicio virtual de las actividades religiosas ha estado marcado por el fuerte impacto de la pandemia, tanto en el barrio donde vive la mayoría de los miembros de la iglesia como en los miembros de la propia iglesia, con víctimas fatales y grande número de contagiados como mencionado anteriormente.

"J" cuenta en la entrevista que "antes de reiniciar los cultos hemos tenido que reflexionar primero sobre la salvación del alma y del cuerpo, sobre el cuidado de la vida en sentido integral, lo espiritual y lo corporal". Todos los entrevistados/as destacan la importancia del tema de la sanidad del cuerpo que pasó a ser estudiado a partir de los Evangelios de Marcos y Lucas. "L" manifiesta que se sorprendió al percibir la grande preocupación de Jesús por la salud en los relatos de la Biblia. "L" frecuentaba también antes de la pandemia una iglesia bautista en la que no se daba importancia a la salud en la Biblia, e incluso durante la pandemia esa iglesia estaba muy preocupada por volver a los cultos presenciales. Para "S" el tema de la pandemia era imposible que no se abordara en los cultos. Una semana después del inicio de la cuarentena la iglesia reinició los cultos por el "zoom" y "al iniciar el culto preguntábamos a los hermanos cómo estaban. La respuesta nos dejaba fríos y sin saber qué responder porque muchos decían que ellos mismos o familiares estaban con COVID o con síntomas".

En el mes de mayo la iglesia decide formar la "Comisión de Iglesia y Salud" motivados por el grave impacto en la iglesia. "Vimos que la pandemia se iba a prolongar y teníamos en la iglesia varios fallecidos y muchos familiares contagiados" (entrevistada “J”). Desde entonces la iglesia reorganizó y diversifico sus acciones pensando en la mejor forma de resistir a la pandemia y en vista de que no había esperanza de contar con ayuda del gobierno central ni del gobierno municipal.

Pasamos ahora a describir las actividades que se realizaban entre mayo y octubre (mes en que hicimos las entrevistas). La iglesia realiza tres cultos por semana: de "edificación" los domingos, de "oración” los miércoles y de "estudios bíblicos comunitarios" los viernes. Los dos primeros son para 
los miembros de la iglesia y el de "estudios comunitarios es abierto a todos los interesados y el objetivo es crear un espacio para relatos bíblicos de sanidad, orar por los que desean, consolar y animar. Según nos informó "S" esa iniciativa tuvo muy buena recepción pues siempre se encontraba nuevas personas que buscaban consuelo. Todos os cultos se realizan por "zoom" y se ha conseguido mayor participación que antes de la pandemia. Informa " $\mathrm{S}$ " que al principio los adultos mayores tenían problemas para conectarse, pero "aprendieron rápido con la ayuda de hijos y nietos". De hecho, en los videos de los cultos se percibe una importante participación de adultos y adultos mayores. A los que no podían conectarse por la mala señal de internet se gravaban videos cortos de partes del culto y se los enviaban por whatApp.

Además de los cultos mencionados la iglesia ha realizado "talleres de terapia psicológica, terapia física y salud alimenticia". Más adelante nos referiremos a esas acciones. Vamos ahora a analizar el papel de los tres tipos de cultos celebrados. Desde el mes de julio hemos hecho observación, no sistemática, de esos cultos, pero hemos tenido acceso a los videos. La información es abundante y se hace más prolija todavía con las entrevistas. De manera que será necesario escoger un conjunto de temas o cuestiones presentes en las diferentes celebraciones. Lo hacemos tomando como ponto inicial cuestiones presentes en una celebración de duelo y viendo cómo las mismas aparecen en otros cultos y en las entrevistas. Las cuestiones escogidas son: el lugar de la Biblia en esa iglesia de tradición protestante reformada, la comprensión de la pandemia y la sanación, y la experiencia cotidiana con la pandemia. Vamos a analizar esas tres cuestiones intentando conocer los beneficios de las celebraciones religiosas para las personas que participan.

\section{Celebraciones religiosas y salud durante la pandemia}

En los meses en que había más fallecidos la iglesia realizó varios "cultos de duelo" dedicados al consuelo y acompañamiento de los familiares de las víctimas. En la respuesta a la pandemia ha sido muy importante la música y los cantos sobre la esperanza. "L" afirma que "en los cultos de domingo estudiando el Apocalipsis hemos visto que ahí hay un pueblo que canta un cántico nuevo. Y a partir de ahí la iglesia organizó un concierto on-line para apoyar a las personas que están sufriendo. Ahí hemos orado y cantado juntos". "L" tiene un conjunto de música folklórica con instrumentos de la cultura andina, como flauta, zampoña, charango, sicuri y bombo, además de la guitarra. Dos de sus afirmaciones son muy importantes para las 
cuestiones que nos ocupan: "la música nos une, nos consuela, nos conecta". Y "nuestras canciones llevan la misma Palabra de Dios pero musicalizada". El domingo 2 de agosto la iglesia realizó un culto especial denominado "Canto de esperanza en contexto de pandemia". Ese culto fue muy emotivo y duró más de cuatro horas ${ }^{21}$. Participaron niños, jóvenes, adultos y adultos mayores, hombres y mujeres. Hubo oraciones, palabras de consuelo, poesías, canciones, lecturas de partes de la Biblia, un corto sermón, conjuntos musicales, solistas, músicos invitados, carteles que se exhibían en las pantallas con frases como "hermano no estás sólo", "gracias", entre otros. La información del video es muy rica, densa, cargada de emoción y de alegría también. Seleccionamos tres partes del evento que consideramos representativas. Primero, la oración inicial del Pastor ${ }^{22}$, luego la explicación del motivo del culto de parte de una de las dirigentes del evento y, finalmente, la letra de una de las canciones que fue presentada por un dúo de invitados y también por un joven de la iglesia.

El Pastor hizo la siguiente oración inicial:

Queremos darte las gracias, padre amado, por la bendición de reunirnos. Gracias por el vínculo del amor que nos permite encontrarnos mediante la plataforma con hermanos y amigas, hermanos y amigos de distintos lugares. En tus manos ponemos esta celebración y pedimos que tu utilices los cantos para bendición, para esperanza y para sanación de muchas personas que están enfermas.

Como es clásico en la culto protestante las celebraciones religiosas se inician con una oración por la persona que dirige, esta vez fue hecha por el Pastor y todo el grupo guarda silencio hasta el "amén" que sí es colectivo. Llama la atención en esa oración la mención a la plataforma del "zoom" por el cual se agradece. Como para todos los grupos religiosos el lugar de culto es muy importante. En el protestantismo el templo se torna lugar y tiempo sagrada durante los cultos. Pero la pandemia y la cuarentena han obligado a reformular el espacio del culto y esta iglesia se ha adaptado bien a las reuniones virtuales. ${ }^{23}$ En un culto de estudio bíblico el Pastor comenzó con las

21 El vídeo del culto nos fue brindado por los dirigentes de la iglesia.

22 No fue posible entrevistar al Pastor, pero su participación está registrada en los vídeos de los cultos que gentilmente nos fueron enviados por la Presidenta del Consistorio.

23 Diferente de otras iglesias en Lima que a lo lago de la pandemia han actuado beligerantemente contra la prohibición de los cultos enarbolando el argumento de recorte de la libertad de culto (BARRERA 2020) 
siguientes palabras: "En marzo cuando hicimos el último culto en el templo pusimos en la puerta del templo un cartel informando que reabriríamos el templo en abril. Porque fue lo que decía el Presidente Vizcarra. Ya estamos en julio y el templo sigue cerrado, pero la iglesia que somos nosotros estamos aquí. En todos esos meses ya hemos estudiado 8 relatos de salud y enfermedad en la Biblia". En los cultos de estudio bíblico se percibe que los miembros son muy dedicados a la lectura y el estudio de la Biblia, hecho que es común a la tradición protestante. Todo el sistema religioso de la tradición protestante gira en torno al lugar central de la Biblia en el culto (BARRERA 2001). La IEP Comas 13 conserva muy bien esa práctica.

En un culto de oración del mes de mayo uno de los hermanos expresó en su oración una queja muy interesante: "A la incertidumbre, el dolor y la muerte se añaden palabras falsas, inclusive de predicadores, diciendo que es el fin del mundo, que es castigo de Dios por nuestros pecados...". Esas palabras muestran que la iglesia no hace una interpretación apocalíptica de la pandemia y al mismo tiempo expresa una actitud crítica hacia las campañas "negacionistas" y "antivacunas" que comenzaban a multiplicarse. El culto de oración, que reúne alrededor de 20 personas, incluye una primera parte de cantos acompañados de guitarra, lecturas, testimonios, una corta reflexión sobre el interesante tema del "luto de Jesús por la muerte de su amigo Lázaro”. En seguida se presentan los motivos específicos de oración y la dirigente los distribuye. Cada uno/a ora por un motivo específico. Las palabras de las oraciones muestran que todos tienen una comprensión bien informada de la realidad de la pandemia. Eso confirma, al mismo tiempo, que la exposición de las personas al virus ha sido forzada por la necesidad de trabajar. En uno de los cultos de oración presenciamos la enorme alegría por la presencia de un hermano en el culto que se había recuperación después de permanecer cerca de un mes en tratamiento. El mismo relató que los exámenes mostraron que sus pulmones estaban bastante comprometidos, que ya estaba mejor y que sus familiares, diferente de lo que afirmaban los médicos habían permanecido asintomáticos, pero ninguno se había podido hacer la prueba para verificarlo. De manera que los cultos de oración son también para agradecer por la recuperación de personas que fueron contaminadas por el virus y para sociabilizar la alegría de haber sobrevivido.

También es notorio que la celebración no se restringe a los miembros de la iglesia. Es también para "amigos y amigas". De hecho, al inicio de ese culto, como en otros, los dirigentes anuncian que el link de la reunió podía 
ser compartido con otras personas. Diferente de una reunión en un espacio físico real el espacio virtual permite la interacción desde cualquier lugar. Y es notorio que la gran mayoría de personas que participaban ya se habían habituado a prender y apagar sus audios y videos, a compartir pantalla, a intervenir con símbolos, etc, de manera que la interacción era bastante ágil. Otro aspecto, de esa oración primera, es la referencia la "sanación de muchas personas que están enfermas". El "Canto de esperanza en contexto de pandemia" se presenta como útil para la sanación. La comprensión que el grupo religioso tiene de la enfermedad y de la sanación no se limita al aspecto físico sino también al aspecto psicológico y espiritual. Eso queda confirmado con la realización de talleres de terapia, como veremos adelante.

Veamos ahora la participación de la dirigente "A" en la celebración "Canto de esperanza en contexto de pandemia". Ella intervino con las siguientes palabras:

"Canto de esperanza" es el nombre que le pusimos a esta reunión porque la esperanza es el horizonte que perseguimos como comunidad cristiana. Esta reunión está dedicada a las familias que están pasando sufrimiento y a las que el dolor embarga diariamente sus hogares. Para ustedes especialmente queremos que el canto y la música sea un camino para fortalecer la fe en el Dios de la vida. Queremos poner alegría y esperanza en sus hogares. Animarles a seguir adelante en el proceso de sanación del cuerpo y de la mente. El canto y la música ayudan a activar hormonas de nuestro organismo para combatir la ansiedad, el miedo y la depresión. Dios atiende nuestra oración y sana nuestras dolencias. Pero es importante organizarnos, cuidar a las familias y guardar el distanciamiento físico, mantener las recomendaciones médicas y sobre todo ser solidarios en este contexto de pandemia. Bien lo dijo el profeta Habacuc "Aunque la higuera no florezca ni en las vides haya frutos, aunque falte el producto del olivo, con todo yo me alegraré en Jehová. Me gozaré en el Dios de mi salvación. Jehová es mi fortaleza.

Llamamos la atención, en primer lugar, a la esperanza como horizonte de referencia comunitaria en medio de tamaña adversidad. La comunidad religiosa logra superar la desesperación que podría llevar al "sálvese quien pueda". El sentido comunitario que el culto evangélico recupera está presente a pesar de la distancia. Es en ese contexto que se entiende a esperanza. Es la esperanza compartida. Muy importante en el contexto de grande desesperación provocada por la pandemia y el abandono del Estado especialmente a los más pobres. La celebración tiene el objetivo de "poner alegría y esperanza en los hogares". 
Nótese también que habla de la sanación como un proceso y tiene que ver no sólo con el cuerpo sino también con la mente. No se entiende la sanación como un milagro repentino. Ni tampoco la pandemia como castigo. De hecho, una de las preguntas a los/las entrevistados/as fue si la iglesia entendía la pandemia como castigo de Dios. Las respuestas fueron muy semejantes: "pandemias siempre ha habido en la historia", "es una enfermedad real", "no se puede negar como otras iglesias que afirman que el COVID es falso", entre otras. También la sanación que se extiende a la mente y no sólo al cuerpo ha sido muy importante en las reacciones de esa iglesia para resistir al virus. Además de los cultos han organizado diversas otras actividades para cuidar específicamente de los efectos psicológicos causados por la pandemia. Dios aparece como "el que sana nuestras dolencias", pero en seguida se subraya "es importante organizarnos para cuidar a las familias, guardar el distanciamiento y seguir las orientaciones médicas". En diversas fuentes de información para este estudio hemos encontrado la importancia que la iglesia otorga a la organización. En efecto la "Comisión Iglesia y Salud" surge de la necesidad de organizar acciones para resistir a la pandemia que se prolongaba mucho más de lo esperado. La organización de los cultos virtuales y los talleres de terapias muestran claramente que no había nada de improvisación. Al contrario, todo estaba muy bien organizado y registrado. Las celebraciones eran divulgadas en el Facebook con antecedencia y me permitieron hacer observación de los mismos. Los links de los videos estaban bien organizados y me facilitó mucho el trabajo de pesquisa para este estudio.

Dos cosas más sobre esa intervención. Además de seguir las recomendaciones médicas, del guardar el distanciamiento y de la organización se afirma "pero sobre todo ser solidarios en estos tiempos de pandemia". Sin duda muy importante. Ven en la solidaridad un deber, una prioridad, una motivación, una fuerza extra de quien cuenta con poco. Todo recuerda la clásica idea de Émile Durkheim: el creyente que comulga sale del culto convencido de puede más y es capaz de hacer lo que no se atrevería sin haber pasado por la experiencia de la comunión. Con mucha razón afirmaba Durkheim que la religión no era un simple sistema de ideas y sí un verdadero sistema de fuerzas movilizadoras (DURKHEIM 2001). La intervención termina con una citación bíblica que remite a la alegría, el gozo, salvación y fortaleza a pesar de las circunstancias adversas. Se constata un conjunto de convicciones, reflexiones, análisis y acciones que muestran la fuerza movilizadora de la religión como fenómeno colectivo. 
En seguida reproducimos, para luego analizar por lo menos un aspecto, la letra de la canción cantada hasta dos veces en la celebración y que ya era parte del repertorio musical de esa iglesia antes de la pandemia, pero que durante la misma se ha tornado más significativa:

Porque él entró en el mundo y en la historia, porque él rompió el silencio y la agonía. Porque llenó la tierra de su gloria, porque fue luz en nuestra noche fría. Porque él nació en un pesebre oscuro, porque él vivió sembrando amor y vida. Porque quebró los corazones duros y levantó las almas abatidas.

Por eso es que hoy tenemos esperanza. Por eso es que hoy luchamos con porfía, por eso es que hoy miramos con confianza el porvenir en esta tierra mía. (Estribillo)

Porque atacó ambiciosos mercaderes y denunció maldad e hipocresía. Porque exaltó a los niños, las mujeres y resistió a los que de orgullo ardían. Porque llevó la cruz de nuestras penas y saboreó la hiel de nuestros males. Porque aceptó sufrir nuestra condena y así morir por todos los mortales.

Porque una aurora vio su gran victoria sobre la muerte, el miedo y la mentira. Ya nada puede detener su historia y de su reino eterno la venida.

Vamos a tratar apenas de un aspecto de esa canción intentando explicar su importancia en esa iglesia que la canta con mucho fervor y la vive. El estribillo, diferente del resto de la canción, tiene un ritmo más rápido y marcial. Nótese que todas las estrofas comienzan con un "porque..." que da inicio a una explicación de razones. Ya el estribillo comienza con un "por eso..." que lleva a las consecuencias, a los resultados, a la acción que se apoya en las razones previas. Se afirma que se tiene esperanza, que se lucha porfiadamente y que se mira al futuro con confianza. Como todo lo que acontece en un acto colectivo religioso es siempre difícil y siempre parcial la explicación de su impacto en el grupo que lo ejecuta. Pero podemos imaginar su importancia en el contexto de pandemia, del dolor, del sufrimiento, de las muertes, de los contagiados y, sobre todo de la incertidumbre frente al hecho real de que no todavía no existe una vacuna y la desprotección del Estado. Es importante recordar que quien canta esa canción son personas que carecen de seguro médico, que no cuentan con recursos para correr a una Clínica particular en caso de contagio. Son personas que no han recibido ayuda del Estado y saben que no la recibirán. Una de las preguntas de las entrevistas era por la opinión que tenían de la gestión de la pandemia de parte del Estado. Las respuestas muestran que el grupo está plenamente consciente que el Estado tiene abandonado a la población más vulnerable. Así, "R" habla del 
"abandono de la salud desde hace años", que "las clínicas se negaron a dar atención", que "los hospitales colapsaron". La entrevistada "J" afirma que la ayuda prometida por el Estado ha llegado a muy pocos entre los más pobres, que lo mismo ha sucedido con las pruebas para detectar infectados. Sólo una pequeña cantidad de pruebas se han hecho en algunos lugares del distrito. También lo destaca "J" que en el distrito de Comas hay población que no tiene ni acceso directo al agua. De manera que es en ese contexto que debe entenderse la importancia del contenido de esa canción en el culto virtual.

\section{Terapias "seculares" y ayuda material promovidas por el grupo religioso}

En esta parte nos referimos a un conjunto de acciones que la iglesia de Comas Km 13 realiza para enfrentar la pandemia. Son acciones organizadas por la "Comisión Iglesia y Salud", que surgió en el mes de mayo, y que expresan la comprensión de la sanidad y de la enfermedad de forma integral entre cuerpo, mente y espíritu. Las llamamos de "seculares" y "materiales" en el sentido simple de que no son parte del culto. Organizaciones no religiosas de la sociedad civil también podrían hacerlo y de hecho lo hacen. Comenzamos con la ayuda material. La iglesia se organizó para ayudar con canastas básicas a la población más pobre de la iglesia (y también fuera de ella). Se organizó lo que llamaron "El kilo de amor". Cada hermano/a que podía donaba 1 kilo de cualquier alimento. Con lo recaudado se hacían las canastas y se entregaban a las familias más vulnerables. La iniciativa ha continuado a lo largo de la pandemia con especial atención a las familias cuyos miembros no han podido retornar al trabajo por ser parte de la población más vulnerable. De esa forma han logrado reducir la exposición de los más vulnerables al virus. También han organizado un fondo de ayuda económica con dinero donado por los miembros de la iglesia que han logrado seguir trabajando. Los líderes de la iglesia organizan la distribución según las urgencias de las familias.

La iglesia también viene realizando un conjunto de "talleres" ofrecidos virtualmente a todos los interesados. Son tres tipos de talleres: de alimentación saludable, de terapia física y de terapia psicológica. Son charlas seguidas, de preguntas y respuestas, ofrecidas por profesionales contactados por los líderes de la iglesia y que lo hacen de forma voluntaria, sin ningún costo pues tampoco tendría la iglesia forma de pagar por ese servicio. Como ya estaba haciendo observación de campo (virtual) participé de una 
de cada tipo de taller. Una médica dio un taller sobre alimentación saludable explicando con detalles los beneficios de una alimentación saludable durante la pandemia. Como resultado del mismo el "kilo de amor" dio un paso de grande osadía pasando a organizar canastas básicas con alimentos saludables. Un importante logro fue tomar consciencia de que comida más saludable no implica necesariamente mayor costo.

Los talleres de terapia física tenían el objetivo de aprender a hacer actividades físicas dentro de casa, sin necesidad de mucho espacio y con accesorios que hay en toda casa. Esos talleres han sido muy importantes para todos los participantes en general, pero especialmente para los adultos y adultos mayores. Se trata de una excelente iniciativa por el confinamiento obligatorio que ha reducido drásticamente la movilidad de las personas. El grupo aprendió que en un espacio de apenas 1 metro cuadrado podía hacer una buena sesión de ejercicios físicos sin ningún costo. Entre los beneficios también debe considerarse sus efectos en la salud mental en contexto de pandemia y, en particular para la depresión en los adultos mayores. Varios de los entrevistados mostraron su satisfacción de ver a los abuelos de la familia participando de esos talleres. Personas de todas las edades podían encontrarse en horario determinado para una actividad lúdica con sus propios cuerpos. De hecho, la iniciativa fue muy bien recibida y la participación se amplió hacia otras familias que no eran de la iglesia.

Los talleres de terapia psicológica eran ofrecidos por psicólogos y consistía en orientaciones generales de cómo prevenir o lidiar con la depresión, la ansiedad, el estrés y el malhumor. La receptividad también ha sido muy buena y aunque no tenemos condiciones de evaluar sus efectos reales sí se puede afirmar que fue muy importante para ayudar a comprender o detectar un cuadro de ansiedad o estrés y distinguirlo de uno de depresión. También siempre hubo la recomendación de buscar ayuda para tratamiento posterior y el psicólogo se mostró dispuesto a continuar conversando en particular con las personas que lo solicitaban.

\section{Consideraciones finales}

La información revisada sobre las acciones de la IEP Comas 13 muestra que la pandemia y el confinamiento obligatorio exigieron cambios drásticos en las actividades de la iglesia. El primero y más inesperado fue tener que cerrar el templo y no poder reunirse en el lugar de culto desde el mes de marzo, pues diferente de otras iglesias en Lima ésta acató y respeto 
las decisiones del gobierno en relación a los cuidados que la situación exigía y exige. El reinicio rápido, al cabo de una semana, de cultos en forma remota muestra que el grupo religioso tiene importante capacidad de adaptación a esa circunstancia inédita. También ha quedado demostrado la capacidad de reacción organizada de esa iglesia ante el duro impacto de la pandemia en la vida y la salud de sus miembros. Los miembros de esa iglesia viven en el Distrito de Comas, en donde la iglesia fue fundada en los años setenta, y son conocedores de las condiciones sociales y económicas del lugar, estudiado en la primera parte de este texto, en consecuencia, conocían también la vulnerabilidad a la que estaban expuestos sus miembros.

Sería muy difícil, sin embargo, que el grupo haya podido siquiera imaginar la gravedad del impacto en número de vidas, de contagiados y de mayor exposición a la pobreza. Ese hecho hace más notorio su capacidad de reaccionar ante la pandemia, tanto en la reformulación de las formas de culto como en los contenidos y sentidos de los mensajes y rituales religiosos que pasaron a realizarse de forma virtual. En un primer período, durante los primeros meses de la pandemia, todas las actividades religiosas se orientaron al consuelo, el luto, la compañía espiritual y la comprensión de la sanidad y la enfermedad a partir del estudio de pasajes de la Biblia que trataban sobre la sanación. El grupo se distingue claramente de una tendencia (aparentemente) mayoritaria en el campo evangélico limeño a interpretar la situación de pandemia en sentidos apocalípticos o "negacionistas" que a lo largo del año (2020) fueron ganando fuerza inclusive en los medios de comunicación y en sectores de la clase política conservadora. En un segundo momento, a partir de la creación de la "Comisión iglesia y salud" en el mes de mayo la iglesia pasó a actuar de forma más estratégica y organizada con el objetivo de resistir colectivamente al enemigo mortal que se mostraba cada vez más letal en la iglesia y en el distrito de Comas. Como mostrado en la tercera parte de este texto, detectamos que ellos y ellas desarrollaron de forma muy creativa dos frentes de acción. Uno de reflexión bíblica, consuelo y oración orientado a fomentar la esperanza a pesar de la difícil situación. Otro de capacitación, orientación y acción orientado a ampliar la comprensión del sentido de la salud y la enfermedad en los campos de la alimentación, la actividad física y la salud mental. 


\section{Bibliografía}

BARRERA, Paulo. "Religión y COVID 19 en el Perú del Bicentenario. Laicidad de colaboración y reacciones evangélicas a la pandemia", Estudos de Religião, vol. 34 N.2, 2020.

BARRERA Paulo, Tradição, transmissão e emoção religiosa. Sociologia do protestantismo na América Latina. São Paulo. Olho d’Água, 2001

CASTILLO, Luis, La administración del Programa del Vaso de Leche y el derecho alimentario de la niñez, en el distrito de Comas en los años 2016 - 2017. Tesis en gestión pública, Lima, Universidad César Vallejo, 2018.

Drinot, Paulo. La seducción de la clase obrera. Trabajadores, raza y la formación del Estado peruano. Lima, IEP, 2019.

DURAN, Francisco, "El debate sobre la captura del Estado en América Latina y la vuelta del instrumentalismo". In Carlos Pazmiño (Coord) Concentración económica y poder político en América Latina. Buenos Aires, CLACSO, 2020

DURKHEIM, Émile. As Formas elementares da vida religiosa. São Paulo, Paulus, 2001

"FITECA: El corazón de los cerros", 17/08/2018. Disponible en: https://www.youtube. com/watch?v=JxwHgr89Lek

GESTION. "Distritos más poblados a nivel nacional” Gestión, https://gestion.pe/economia/ censo-2017-son-distritos-poblados-nivel-nacional-236829-noticia/?ref=gesr

GOLTE, Jürgen y ADAMS, Norma, Los caballos de Troya de los invasores. Estrategias campesinas en la conquista de la gran Lima. Lima, IEP, 2018

HUAMÁN, Josefina et al. "Los nuevos desafíos de la ciudad para las mujeres y la visibilidad de su participación en la construcción del habitat: el caso del cono norte". JOSEPH Jaime. (1999), Lima Megaciudad. Democracia, desarrollo y descentralización en sectores populares. Lima, ALTERNATIVA y UNRISD, 1999.

INEI, Una mirada a Lima metropolitana, Lima, INEI, 2914. Disponible en: https://www.inei. gob.pe/media/MenuRecursivo/publicaciones_digitales/Est/Lib1168/libro.pdf

JOSEPH, Jaime, Lima Megaciudad. Democracia, desarrollo y descentralización en sectores populares. Lima, ALTERNATIVA y UNRISD, 1999.

KESSLER, Juan, Historia de la evangelización en el Perú. Lima, Puma, 1993.

KOWARICK, Lúcio, Viver em risco. Sobre a vulnerabilidade socioeconômica e civil. São Paulo, Editora 34, 2009

STIGLITZ, Joseph, O Preço da desigualdade. Lisboa, Bertrand, 2013

TANAKA, Martin. "La desigualdad en las ciencias sociales peruanas: itinerario y temas de la agenda actual", en: COTLER Julio y CUENCA Ricardo, Las desigualdades en el Perú: balances críticos. Lima, IEP, 2011.

WILLAIME Jean-Paul, La précarité protestante. Genève, Labor et Fides, 1992.

Submetido em: 20-8-2021

Aceito em: 10-9-2021 